\title{
¿Ha muerto la teología de la liberación? La realidad actual y sus causas (II)
}

\author{
Pedro Trigo, \\ Centro Gumilla, \\ Caracas, Venezuela.
}

\section{1. ¿Un nuevo comienzo o una postura equivalente?}

En un artículo anterior ${ }^{1}$, hemos revisado la novedad de la teología de la liberación, en estas dos últimas décadas. Ahora nos preguntamos por su futuro. De modo general, podemos afirmar que eso dependerá de cómo se sitúe hoy el teólogo -y el agente pastoral-, en relación con la época en que, en el pasado, surgió la forma de hacer teología que se llamó "teología de la liberación". Veámoslo.

Si el teólogo de hoy pensase que nada ha cambiado en nuestro mundo y que, por eso, debe seguir haciendo lo mismo que hacía en épocas pasadas, podrá sobrevivir y seguir trabajando en su profesión, pero su teología y su pastoral serán anacrónicas. No serán tenidas en cuenta por quienes viven en esta nueva época, pues sentirán que ya no se dirigen a ellos. El teólogo estancado en la época pasada podrá estar hablando a quienes todavía no han empezado a vivir en la época actual, porque no han podido asumir sus bienes civilizatorios y culturales, quizás porque ni siquiera se han percatado de su existencia, o porque los rechazan totalmente. Pues bien, si los que piensan ser teólogos de la liberación se desentienden de la época actual, se mantendrán en lo más externo y superficial de la realidad de hoy, pero no podrán influir sobre ella, ni podrán sumar fuerzas con quienes luchan por transformarla. Una teología así, surgida en el pasado y mantenida a base de pura voluntad en el presente, podrá poseer su propia grandeza y, si es de suficiente calidad, quizás sea reconocida y aprovechada por quienes vendrán después, aunque tendrá que pasar algún tiempo para que esto ocurra.

1. “¿Ha muerto la teología de la liberación? La realidad actual y sus causas (I)”, Revista Latinoamericana de Teología 64 (2005) 45-74. 
Ahora, en esta época, su función se limitará a ayudar a resistir a quienes no han pactado sin más con lo que propone la época en que vivimos, lo cual no deja de ser una función legítima y digna, pero también limitada.

Por otra parte, si el teólogo de hoy se comprende como continuador de la época anterior, aunque ahora viva más en la oposición social, porque cree que en la figura histórica dominante es mucho más lo malo que lo bueno, entonces, tiene que plantearse cómo encontrar, en la época actual, lo equivalente a lo que se planteó en la época pasada. La tarea que tienen por delante estos teólogos de la liberación es volver a decir, pero con creatividad fiel, lo que se dijo en décadas pasadas; más aún, tienen que seguir adoptando la misma perspectiva que guió su teología en el pasado, pero desde la novedad histórica en que vivimos. Es ésta una tarea mucho más compleja que la de los teólogos de la liberación anteriores, pero su aporte puede ser muy fructífero. Puede fecundar a quienes, desde la inspiración cristiana, quieren vivir con responsabilidad, en esta época, ayudándolos a no contentarse con paliar el costo social del sistema actual y a no justificar esa actitud, corrigiendo sólo en alguna medida sus efectos más devastadores.

Esta teología de la liberación de hoy tendrá como objetivo desenmascarar la dimensión fetichista de la dirección dominante que toma la figura histórica actual e insistir en que es expresión de una situación de pecado ${ }^{2}$. Pero debe mostrar también aquellos bienes civilizatorios y culturales presentes, en la nueva época - y el modo de cultivarlos-, precisamente para que ésta cambie su dirección fundamental. En cualquier caso, la teología de la liberación de hoy debe proponer un modo de vida alternativo al actual, de tal forma que vivir en la oposición sea también posible hoy, sea humanizante e incluso gratificante, a pesar del precio que haya que pagar.

Además, para que esta teología de hoy sea cristiana, tiene que ofrecer la conversión como buena nueva también a quienes oprimen, sacrifican y excluyen a los demás. Es decir, éstos tienen que convertirse a un mercado no totalitario, ni fetichista, a una democracia más efectiva, al reconocimiento de los tenidos como subalternos y excluidos, al reconocimiento de los derechos humanos de todos y de los derechos de la tierra. Y muy específicamente, al cultivo de otras dimensiones del ser humano, como son poner las capacidades propias al servicio de los demás, promover la relación gratuita, la fiesta, el silencio, la contemplación y la oración.

Si las nuevas generaciones de teólogos pensasen que, como la época es nueva, hay que hacer borrón y cuenta nueva con lo que antes se pensaba, la teología

2. Deberá hacerlo de modo que no contribuya a robustecer esa dimensión fetichista al escribir desde la fijación en el fetiche, blasfemando de él. La postura cristiana es devolverlo a la fluidez de lo histórico. Ver Trigo, "Mística y profecía en la vida religiosa hoy", ITER 35 (2004) 100-105. 
de la liberación moriría, de hecho, con la última generación de sus actuales cultivadores. Y también es muy importante estar claros sobre la verdadera dificultad que las nuevas generaciones tienen con la antigua teología de la liberación. Esta consiste en que la encarnación kenótica de la institución eclesiástica latinoamericana, de los obispos y de los demás agentes pastorales y, en particular, de los teólogos, resultó realmente traumática. El cambio de lugar social, no como algo sólo ético y menos aún supererogatorio, sino como prenda de fidelidad cristiana elemental, es siempre la cruz de la teología y de todo proyecto pastoral. Ciertamente, fue cruz para la teología y la pastoral de la liberación de hace unos años.

Es comprensible, pues, que, tras los graves conflictos de estos últimos años, a la mayor parte de la institución eclesiástica, a los obispos, a los responsables de la vida religiosa y a quienes dirigen las facultades teológicas eclesiásticas les parezca más prudente seguir ayudando a los de abajo, sí, pero desde arriba, desde sólidas instituciones no manejadas por el pueblo, aunque se piense que son para el pueblo.

Es cierto que en el pasado no siempre se hicieron bien las cosas. Todo era tan nuevo y la realidad que se vivía era tan radicalmente injusta y producía efectos tan negativos, que hubo la tentación de apurar demasiado el paso, saltando procesos necesarios, y se cometieron errores. Pero no fue esto la razón verdadera de la estigmatización, marginación e incluso persecución. El motivo de fondo por el cual se persiguió a la Iglesia fue, simplemente, como hemos insistido, por colocarse del lado de los pobres, por cambiar de lugar social. Y hay que aclarar que no fue tanto por abandonar a los no-pobres, de lo cual se la solía acusar. Lo que no gustó es que buscó evangelizarlos desde abajo, como lo había hecho Jesús. En definitiva, la persecución fue por fidelidad al evangelio. Pero hay que insistir en que, si queremos seguir siendo cristianos, no hay otro camino. Dios no quiere que los de abajo sean subalternos, ni en la sociedad, ni en la Iglesia. No es una alternativa cristiana ayudar a los pobres, reduciéndolos a meros destinatarios de la acción de la institución eclesiástica, ni tampoco del Estado o de las organizaciones no gubernamentales. Debemos querer y buscar muy de veras la salvación de todos, también la de los de arriba. No quererlo no es cristiano, pero tampoco lo es pretender buscar su salvación, perteneciendo a su mundo.

La teología de la liberación es pascual y la cruz siempre tiende a evitarse. Éste es el principal problema de esta teología, pero es también la razón por la cual es irrenunciable. Y en este contexto, quisiera justificar por qué es irrenunciable la fidelidad a la época anterior, por qué no hay que dejarla en paz, por qué tenemos que mantener la referencia a ella, aunque no de modo fundamentalista, sino con fidelidad creativa. Creo que, por lo general, quienes están en contra de mantener esas fidelidad no se hacen esta pregunta, sino que dan una respuesta negativa, sin más explicaciones. Pero es necesario hacerlo. 
En primer lugar, hay que plantearla por una razón general: la historia no puede concebirse como una sucesión de unidades estancas, que nacen desde sí mismas y mueren cuando ya han dado de sí, sino como transformaciones más o menos profundas de lo dado. El pasado nos entrega posibilidades, planteamientos, exigencias; nos posibilita y a la vez nos responsabiliza. Y a su vez, el futuro nos atrae, nos provoca a tendernos hacia él. El presente se sitúa dinámicamente entre ambas dimensiones. La nueva época en que estamos ha nacido de la anterior, tanto de sus posibilidades como de sus estrecheces. Y por eso, la referencia a ella ayuda a hacerse cargo de las potencialidades con las que hoy contamos y de las tareas que nos aguardan.

En el caso de la teología de la liberación, sin embargo, hay una razón muy específica. En la época pasada, la Iglesia latinoamericana nació como sujeto histórico, que toma conciencia de sí, que se expresa y se propone un proyecto histórico, en fidelidad creativa al evangelio y a las mujeres y varones del continente. Nació con tal prestancia y ejemplaridad que se convirtió en buena nueva para el pueblo latinoamericano y para muchos otros de buena voluntad. Se convirtió también, como Jesús, en bandera discutida, ya que los opresores no quisieron escuchar su voz, sino que la calumniaron y persiguieron. Fue también estímulo para otras iglesias hermanas y para personas y grupos que, en sus sociedades, luchaban por un mundo con justicia.

Podemos decir que la Iglesia latinoamericana que se expresó en Medellín y Puebla fue, en efecto, sacramento histórico de salvación, cosa que no suele ser ninguna Iglesia particular, por el mero hecho de vivir según la normativa institucional. Lo fue por seguir a Jesús de Nazaret, por proseguir su historia, en su propia circunstancia. En realidad, esta Iglesia fue Iglesia de todos, pero como Iglesia de los pobres, tal como Juan XXIII había deseado que lo planteara el Concilio. En ella floreció una pléyade de pastores, verdaderos padres de la Iglesia, como no se había dado desde el tiempo de los fundadores de esta Iglesia; y junto con ellos, se dio una eclosión de carismas y ministerios: servidores de la palabra, presidentes de asambleas, catequistas, animadores de comunidades, ministros de la caridad, constructores de un renovado tejido social, luchadores por la justicia, profetas, doctores y, sobre todo, mártires, el mayor don de Dios a una Iglesia, el mayor signo de fidelidad, la mayor cantera de fecundidad. Como sucede siempre en la historia, esta ingente riqueza estuvo acompañada de errores y pecados, pero los frutos fueron excelentes.

Pues bien, la teología de la liberación expresa ese proyecto pastoral que cristalizó en Medellín, y en la línea mayoritaria que se expresó en Puebla. Ella es la teorización más consecuente de este pentecostés que vivió nuestra Iglesia. No hay que caer en el simplismo de comprender como equivalentes la teología latinoamericana y la teología de la liberación, pero ésta fue, sin duda, la línea principal de aquella época y, por tanto, de la teología latinoamericana. Ahora, en 
América Latina, se hace cada vez más teología; pero, así como no toda la teología que hacen las mujeres es teología con conciencia de género, así tampoco toda la teología que se hace en América Latina se hace desde América Latina, siendo así que la región es lugar teológico. Teología latinoamericana sólo es la que se hace desde América Latina. No pretendemos que toda la teología que se hace desde la realidad de la región sea teología de la liberación, pero por ahora, sí lo es, en su mayor parte, y, a nuestro modo de ver, es la teología más significativa.

Por todas estas razones, no podemos hacer borrón y cuenta nueva del pasado. Es nuestra riqueza y ella nos llena y nos obliga. Pero como esta época no es la misma que la que nos tocó vivir hace unos años - y que, en una medida modestísima, contribuimos a construir-, tenemos que enfrentar la época actual con la misma creatividad fiel con la que nos enfrentamos a la del pasado. Tenemos que encontrar la nueva correlación del seguimiento: Jesús es a su época como la Iglesia primitiva a la suya, como el Vaticano II, Medellín y Puebla a la suya, como esa teología equivalente que tenemos que inventar a la nuestra. Y hay que insistir en que este equivalente tenemos que inventarlo. Decir y hacer lo mismo que antes, como si nada hubiera pasado, no sería fidelidad, sino fundamentalismo. Como tampoco es fidelidad plegarnos al mercado y hacer lo que demanda de nosotros. Estamos contentos de lo vivido, y buscamos ser fieles. Pero, para seguir en el mismo camino, tenemos que reinventar la equivalencia.

\section{Líneas maestras de la equivalencia}

\subsection{Hacer teología desde el ser afectado y exigido por los pobres}

¿Por qué decimos que hoy sí existe teología de la liberación? Porque hay teólogos que se remiten a la realidad actual con el mismo pathos y ethos de la época fundacional. Esto es decisivo. Si falta, la elaboración teológica se reduce a escolástica, a práctica académica que, en el mejor de los casos, podrá ser rigurosa y bienintencionada, pero no pasará de ser un mero producto intelectual. Puede aludir, muy correctamente, a la realidad, pero sin poseer su densidad, sino reduciéndose a ser una mera referencia a ella.

Ese pathos y ese ethos siguen siendo decisivos, porque la inhumanidad de nuestra época es tan pavorosa que, ya que no puede ocultar los desmanes, necesita insensibilizar a la gente. Hoy se logra que la gente sepa lo que ocurre, al menos sus consecuencias más clamorosas, e incluso que vea las escenas más hirientes, pero al mismo tiempo se logra que la gente no quede herida por tanto horror, sino que el horror quede neutralizado. Los mass media logran - no por casualidad, sino como objetivo buscado tras paciente investigación - inmunizar a los espectadores, y para eso consiguen des-realizar lo que presentan en pantalla. Así, en el ambiente, incluso los bienpensantes viven la realidad con una cierta atonía. Es cierto que, de vez en cuando, se ofrece una catástrofe con todo deta- 
lle. Entonces, la gente se emociona, después se le facilita una pequeña catarsis y vuelve a la normalidad. Se ha logrado que diversos grupos de personas queden confinadas en su mundo y prescindan, de hecho, de todo lo demás. Se cumple el antiguo dicho "ojos que no ven, corazón que no siente". Y cuanto más poder adquisitivo se tiene, tanto más se aísla uno del mundo. De este modo, se puede incluso vivir en paz con la propia conciencia.

Las reglas de juego de esta sociedad se imponen con tal contundencia que, aunque muchas personas desearían con sinceridad otra cosa, acaban resignándose ante el poder, a la vez seductor y aplastante, de aquéllas. Pero además del poder - que se presenta como inapelable-, hay otra característica en la dirección dominante de esta figura histórica de nuestro mundo actual que contribuye de una forma muy eficaz a que se dé la neutralidad emocional descrita: el predominio abrumador de las relaciones entre cosas sobre las relaciones entre personas. Tal como denunciaba Marx, en la primera sección de El Capital, dedicada al fetichismo de la mercancía, ésta se nos presenta llena de valor, mientras que las personas son percibidas como cosas, la mayoría de ellas con muy escaso valor en el mercado, o sin valor alguno. Pues bien, hoy lo que más vale no son ni siquiera las mercancías, sino las acciones en alza. Y de tal modo valen que, para que sigan en alza, todo puede ser sacrificado. En primer lugar, los trabajadores. Pero la mayoría ni siquiera es sacrificada, sino que simplemente es descartada. La situación es tan inhumana que quienes llegan a la categoría de explotados se sienten privilegiados. Y todo ello, aunque es bien conocido, permanece oculto. Sólo se exhibe el estado satisfactorio de las corporaciones y las mercancías. Lo que se pone ante nosotros son cosas, para que nos relacionemos con ellas. Y ésas son las relaciones que hacen que nosotros tengamos valor. Las relaciones con las personas son sólo privadas y, de algún modo, supererogatorias. En la dirección dominante de esta figura histórica no existen vínculos obligantes. $\mathrm{La}$ fe, la confianza y el sacrificio no se dirigen socialmente a las personas, sino a aquello que tiene valor: el mercado ${ }^{3}$. En él se pone la mayor carga de pasión y de exigencia.

En este mundo, quien se plantee en serio dónde dormirán hoy los pobres ${ }^{4}$ será considerado como un sentimental o un inadaptado. $\mathrm{Y}$ quien lo pretenda

3. Dice Jung Mo Sung: "si estamos atentos a los discursos de los economistas, de los políticos y de los comentaristas, es bastante normal oír de sus bocas palabras como 'fe' (en el mercado), 'sacrificios' (exigidos por las leyes del mercado), o 'no hay salvación' (o camino) fuera del mercado. Uno de los conceptos fundamentales en esta critica es el de la idolatría del mercado" ("La teología y la vida de los pobres", en Panorama de la Teología Latinoamericana, Estella, 2001, p. 371). Ver también del mismo autor, Deseo, mercado y religión, Santander, 1999. Ver también Hinkelammert, "La teología de la liberación en el contexto económico-social de América Latina: economía y teología o la irracionalidad de lo racionalizado", Cristianismo y Sociedad 120 (1994) 59-87.

4. Gustavo Gutiérrez, Páginas 87 (1987) 2 y 35. 
plantear como perspectiva permanente, es tenido como un terrorista mental, un perturbador de oficio, un tipo peligroso de quien hay que huir. Una persona que viva con esta pregunta a cuestas, es alguien que podrá vivir en este mundo, pero que no es de él, pues no se define por la lógica ambiental. Sin embargo, ése es un verdadero sujeto, un ser humano, que ha liberado su libertad y que la aplica a un propósito concretísimo y trascendente.

Pues bien, quien hace teología desde esa pregunta real y densa, desde ese estar de una forma radical afectado y exigido por las personas, no por las cosas, y especialmente por las personas que valen menos en el mercado o que no valen nada, ése hace teología de la liberación. Y ello es así, no, en primer lugar, por las conclusiones a las cuales llega, sino por ese núcleo de verdad insobornable, que pone en movimiento el pensar y que no lo deja conformarse con conclusiones convencionales. El que hace teología desde esas entrañas conmovidas por esos pobres reales, que reclaman con urgencia una toma de posición vital, ése vive su quehacer teológico como acto segundo. Y es "segundo" no sólo porque, cronológicamente, viene en segundo lugar, sino por su referencia real y estructural al acto primeros.

\subsection{Teología como inteligencia de la misericordia, de la gracia, de la libera- ción}

Antes he citado la pregunta que hace Gustavo Gutiérrez, que aparece como título de un artículo suyo. Pudiera haberme referido, asimismo, a la insistencia machacona de Jon Sobrino de subtitular lo que escribe como teología desde las víctimas ${ }^{6}$. Esto que podemos llamar un trascendental de la teología de la liberación es tan determinante que da lugar a otro modo de entender la teología, la cual no sería tanto intellectus fidei, sino intellectus misericordiae ${ }^{7}$, el cual puede traducirse también como intellectus gratiae e intellectus liberationis. No es, pues, un tema, sino, ante todo, una perspectiva, que da lugar a una epistemología.

¿En qué sentido la inteligencia de la misericordia es inteligencia de la gracia? En dos sentidos complementarios. En primer lugar, la misericordia no es un sentimiento que se deriva de un determinado temperamento. Antes que eso, es un estar afectado por una dimensión de la ultimidad de la realidad de Dios; en ese sentido, es el resultado de seguir el impulso del Espíritu, que nos mueve desde más adentro que lo íntimo nuestro. Como lo habían anunciado los profe-

5. Desde La fuerza histórica de los pobres, Gustavo Gutiérrez viene hablando de la teología de la liberación como acto segundo, en el sentido mencionado. Ver también Trigo, "Cuál es el acto primero del que la teología de la liberación es acto segundo", ITER 25 (2001) 109-136.

6. Por ejemplo, La fe en Jesucristo lleva como subtítulo Ensayo desde las víctimas.

7. Jon Sobrino, El principio-misericordia, Santander, 2002, pp. 47-80. 
tas, ese seguir el impulso del corazón, el núcleo de donde brota la posición primordial ante la realidad, es también obediencia. $Y$ antes que obediencia es, como movimiento del Espíritu, don que se nos otorga. Es gracia.

$Y$ es también gracia en otro sentido no menos trascendente. Es gracia porque se recibe de los pobres a quienes se sirve. Dice Juan Pablo II que la misericordia no merece el nombre de cristiana si quien la ejercita no experimenta que él la recibe del mismo a quien se da. Para el sujeto occidental moderno es más fácil vivir para los demás, para los que necesitan de uno, que vivir con ellos, recibiendo también de ellos, es decir, vivir en reciprocidad de dones. En muchos casos se es capaz de llevar a otros, de cargar con ellos, pero no hay capacidad para recibir de ellos, de ser cargado por ellos. Y quien sólo sabe dar es un bienhechor, que, en definitiva, según Jesús de Nazaret y la sabiduría acumulada, bien puede ser un opresor. El único que no oprime es quien no sólo da, sino que también recibe de aquellos a quienes da. Es una tremenda gracia recibir de los necesitados. Esta percepción de que es gracia recibir de quienes uno creía que sólo tenían carencias, es la superación del carácter ilustrado del sujeto.

La inteligencia de la misericordia es también inteligencia de la liberación, porque quienes necesitan de misericordia no sólo tienen carencias, sino que son también oprimidos, excluidos. Por eso, la misericordia hacia ellos no se plasma sólo como un otorgar crecimiento humano, sino también como una liberación. La dialéctica cristiana no es, como la occidental, una dialéctica positiva, que va desde lo bueno a lo mejor, en un ascenso continuo e ilimitado. No va de un tener, saber, poder, valer algo, a un tener, saber, poder y valer siempre más. Esta dialéctica es siempre elitista y deja afuera a las mayorías. Por ejemplo, en la dialéctica platónica, tal como está plasmada en El banquete, donde el deseo va de un cuerpo bello a los cuerpos bellos, de los cuerpos bellos a las almas bellas, de las almas bellas a la Belleza, de la belleza al Bien, y del bien al Uno. La propuesta es fascinante, pero, si no se trata de la mera contemplación de un objeto, sino de un conocimiento interno, de un trato íntimo, es difícilmente universalizable. Y además, ¿qué pasa con quienes sólo son capaces de relacionarse con otros, reduciendo a objeto a la persona poseída? ¿Qué pasa con quienes se atascan y no son capaces de ningún movimiento dialéctico puramente positivo? ¿Qué pasa con quienes, a causa de carencias elementales o de pasiones inferiores -dominar o poseer-, no sienten deseo de la belleza? Todos esos quedan fuera, como seres inferiores. Eso es así, aun fijándonos en el aspecto más noble de la dialéctica, que siempre se ha dado en occidente. Pero junto a esa noción elevada de aristocracia, con frecuencia ha llevado la voz cantante la que reduce el valer al poder y al tener, y encauza el saber a proporcionar los medios para poder y tener cada vez más. La consecuencia de entregarse a esos "demonios" no puede ser hoy más elocuente: la exclusión de la mayoría de la humanidad, la brecha creciente, no sólo entre los países pobres y ricos, sino incluso dentro de cada país. 
La dialéctica cristiana, por su parte, es una dialéctica negativa, porque no toma en cuenta sólo lo positivo para plenificarlo, sino que arranca de lo negativo para superarlo: se propone remediar la carencia de unos y la inhumanidad de otros, se propone liberar a los oprimidos de sus opresores, y liberar también a éstos de su egoísmo e insensibilidad. Es la dialéctica de salvar lo que está perdido: quitar el pecado del mundo y transformar las estructuras que generan opresión y exclusión. La razón de esta dialéctica es que Dios es tanto el Dios de la vida como el Dios que no quiere la muerte del pecador, sino que éste se convierta y viva. El reino de Dios que proclamó e hizo presente Jesús es el mundo fratemo de las hijas e hijos de Dios. Disculparse diciendo, " ¿acaso soy yo guardián de mi hermano?", es la negación más radical de fraternidad. Sería la palabra de un asesino, porque quien borra a su hermano de su corazón ha echado fuera de sí el amor de Dios. Por todo ello, la teología que se concibe como inteligencia de la misericordia se comprende también como inteligencia de la liberación.

Lo genuino cristiano del pathos y del ethos de los que venimos hablando, como acto primero del que brota la teología como un acto segundo, se muestra en contribuir a que los pobres sean sujeto en la sociedad y en la Iglesia. No es misericordia dar de tal modo que se reduzca a quienes reciben a la condición de clientes, por decirlo con el término romano, tan usado en América Latina para caracterizar un tipo de relación social: el clientelismo, que denota y encubre la desigualdad radical y que transcurre al margen de la ley. Esa contribución para que los pobres sean sujetos en lo personal y en lo social, desde su propia condición cultural y espiritual, es la piedra de toque de si una línea pastoral puede ser llamada en verdad liberadora. Lo mismo ocurre en la elaboración teológica: no basta con hablar de opción por los pobres, sino que es imprescindible mostrar de modo sistemático - y fundamentarlo- que ella entraña esta apuesta por la subjetualidad popular, y no sólo en la sociedad, sino en la Iglesia, donde, hoy por hoy, no se da este reconocimiento en el ámbito estructural.

La conclusión es que existe teología de la liberación, porque hoy siguen existiendo teólogos que viven su teología como acto segundo de ese pathos y de ese ethos que son el acto primero. Hoy, hay teólogos que conciben su teología como inteligencia de la misericordia, que es también teología de la gracia y de la liberación.

\subsection{La realidad como lugar teológico fundamental: desenmascaramiento profético y acción para que dé de sí}

De lo anterior se desprende que en la epistemología de la teología de la liberación, el lugar teológico fundamental es la realidad. No es la Biblia, ni la Iglesia, sino la realidad. La voluntad de realidad es en ella algo primario, fontal ${ }^{8}$.

8. Gustavo Gutiérrez tituló significativamente La densidad del presente a una colección de artículos suyos (Salamanca, 2003). Pero es Jon Sobrino quien viene insistiendo 
Con su práctica pastoral y su teología, intenta hacer justicia a la realidad y ayudar a que ésta dé de sí. Le parece que hay que hacerle justicia, porque está oprimida por la injusticia. La realidad se presenta como violentada, como sometida por una fuerza que parece tener una prestancia sobrehumana, pero que carece de verdadera gloria, pues su peso no es de vida, sino de pura imposición.

Hoy, la mayor parte del mundo vive bajo la opresión y la exclusión, en democracia. Éste es un hecho desconcertante, pero macizo. En unos países y para unas personas - los vencedores- esto significa que pueden elegir lo que garantiza sus intereses, prescindiendo de si perjudica a otros, incluso de si los deshumaniza a ellos mismos. Hoy, no se puede ignorar que pueblos enteros son llevados a elegir libremente una mayor seguridad y crecimiento económico, y, además, pagando para ello libremente el precio de una insolidaridad y de una pérdida de sentido humano crecientes. Pero en otros países y personas, en la mayoría - los perdedores-, esto significa que la realidad, tanto la personal como la social, queda oculta a sus ojos, y viven pacífica e incluso confortablemente, en la opinión establecida. Por eso, la teología de la liberación dedica hoy muchos esfuerzos a mostrar el carácter fetichista de la dirección dominante de esta figura histórica y quiere hacer ver la distorsión reinante. De este modo, la teología de la liberación participa de la corriente que se ha llamado de "los maestros de la sospecha". Aunque, tal como dijimos, su pasión y su exigencia son proféticas, al ser obediencia al Espíritu, pues ofrecen una profecía razonada, sistematizada y fundamentada. Dicho con mayor precisión, su inspiración es profética, mientras que sus elaboraciones concretas dependen de la capacidad de cada teólogo para plasmar esa inspiración sin deformarla.

La voluntad de realidad, sin embargo, no puede contentarse con la labor de derribar ídolos y sacar a la luz la verdad que oprime la injusticia. La voluntad de realidad se propone, por todos los medios, que la realidad dé de sí; y ello es así porque, en el fondo, esa voluntad de realidad es constructiva. Por eso, una teología como la de la liberación, que insiste en que la realidad no es simplemente el mundo fabricado por la humanidad, sino que la humanidad está religada, tanto al misterio que la funda como al filum del cual proviene y, en él, a toda la creación, insiste de forma complementaria en que el modo de asumir con responsabilidad esta pertenencia a la realidad es llevarla adelante y salvaguardarla, mediante la acción. No entiende por acción cualquier despliegue técnico, cualquier intervención social, ni tampoco el activismo, sino la acción que salvaguarda y potencia la tierra y humaniza a la humanidad. Por lo que toca a la tierra, asume que no es una mera cantera de recursos, que se explota y se desecha, sino un "sistema de sistemas" del cual provenimos y al cual pertenecemos, no como meras partes de

sistemáticamente en este punto. Un buen ejemplo es su último artículo "Jesús y la justicia", Revista Latinoamericana de Teología 62 (2004) 180-185. 
él, sino asumiéndolo libre y de forma responsable. Es cierto que la humanidad cualitativa es un concepto abierto, pero también es cierto que sí sabemos con certeza qué es lo antihumano, lo que deshumaniza.

La teología de la liberación entiende esta acción como co-incidencia con el Espíritu. El Espíritu es acción, y por tanto, la relación con él no se da en el cara a cara, en la invocación, sino al incidir ambos en lo mismo. En sentido literal, en esto consiste el co-incidir. Esta coincidencia no hay que entenderla como una sinergia, en el mismo plano. En el plano de la observación científica sólo obramos nosotros, porque el Espíritu no es un ser mundano. El Espíritu nos mueve desde más adentro que lo íntimo nuestro, como un movimiento trascendente, en la inmanencia. Y por eso hay que decir que, aun siendo su labor desenmascaradora tan importante, lo decisivo de la teología de la liberación -y en lo que se juega no sólo su fecundidad, sino también su pervivencia - consiste en esta dirección propositiva. Si no tiene nada que decir positivamente, no tiene evangelio, y por tanto, no tiene autoridad cristiana.

\subsection{El Jesús histórico, el reino que él proclama y hace presente, y su cuer- po sufriente en la historia}

Es claro que la teología de la liberación, como movimiento pastoral y como elaboración teológica, ha propiciado un acercamiento a los evangelios. La lectura orante de la Escritura - sobre todo de los evangelios-, en las comunidades eclesiales de base ${ }^{9}$, el que la Escritura fuera fuente de homilías y documentos, y lo específico de las cristologías latinoamericana ${ }^{10}$ son muestra fehaciente de que la inspiración profética de este proyecto pastoral no provenía de la contaminación marxista, sino de las límpidas aguas del evangelio.

Pero hay muchos modos de leer el evangelio. El de la teología de la liberación es desde dentro del círculo hermenéutico, que va de la vida al evangelio y del evangelio a la vida. Lee el evangelio desde el deseo de vivir la vida como

9. La producción más sistemática y difundida es la de Carlos Mesters, Lectura orante de la Biblia, Estella 1997; En camino con Jesús, Estella,1997; Con nosotros está y no le conocemos, Estella, 1999; Querido Teófilo, Estella, 2000; Misericordia quiero y no sacrificios, Estella, 2001; Vivir y anunciar la palabra, Estella, 2001; El sueño del pueblo de Dios, Estella, 2001. Habría que mencionar también los trabajos de Saravia, Caravias, Richard, Díaz Mateos y otros muchos.

10. Costadoat, "Cristología latinoamericana: Bibliografía (1968-2000)", Teología y Vida Vol. XLV (2004) 18-61. Además, Trigo, "El poder de Jesús", ITER 30-31 (2003) 228294 y El poder en perspectiva teológica, Bogotá, Facultad de Teología Universidad Javeriana, 2004, pp. 83-171; P. Richard, "El Jesús histórico en la teología de la liberación", Pasos 100 (2002) 43-49. Resta como tarea componer una cristología de los misterios de la vida de Jesús, no a la usanza medieval, por ejemplo, de Santo Tomás, sino a partir de la narratividad evangélica. 
Dios quiere, en seguimiento de Jesús de Nazaret, y por tanto, al servicio del reino, del establecimiento del mundo fraterno de las hijas e hijos de Dios. El intento serio para estar donde Dios quiere que se esté, y con su mismo Espíritu, es el lugar hermenéutico desde el cual se despliega el evangelio, supuesta, claro está, la mediación exegética imprescindible que, en la mayoría de los casos, puede hacerse sucintamente, no al modo de una larga clase que desvía la atención, sino como una aclaración preliminar. Pero a su vez, esa lectura discipular del evangelio se convierte en luz, que lee la vida y la situación reales, confirmando unas cosas, haciendo avanzar otras y transformando las que, a esta luz, aparecen necesitadas de reforma ${ }^{11}$.

Esa lectura del evangelio está animada por el deseo del encuentro con Jesús de Nazaret, realmente presente en los evangelios, cuando se los lee discipularmente. La relación con Jesús es doble: la contemplación despaciosa e incesante de los evangelios como un fin en sí mismo, es decir, estar con Jesús para ir adquiriendo sus actitudes y su mentalidad por connaturalidad, y el seguimiento, el ir detrás de él, llevando adelante su causa, su servicio al reino.

Hay que decir que, a pesar de la distancia temporal y cultural, existe todavía hoy una cierta homología estructural entre su situación y la del pueblo, que hace que el evangelio se despliegue con profundidad y naturalidad. Y además, hay que tomar en serio la constatación orante y jubilosa de Jesús de que Dios ha ocultado el misterio del reino a los especialistas y lo ha revelado a la gente sencilla. Aunque nos cueste aceptarlo a los teólogos, esto es verdad y uno lo ha experimentado.

Esta lectura orante de la Palabra de las comunidades cristianas populares es una de las tradiciones que, gracias a Dios, han pasado de la época anterior a la nuestra. En no pocas comunidades y grupos, el método se ha ido aquilatando y hoy va dando sus mejores frutos: una enorme coherencia personal, el tesón para entregarse al servicio del reino, en la familia, en el vecindario, en el seno del pueblo, en la labor de ciudadanía y, por supuesto, en la comunidad cristiana, tanto la comunidad cercana como la más amplia y extendida.

Este ejercicio cristiano y este método van ganando terreno en la Iglesia latinoamericana. Sin embargo, quiero insistir en un punto que me parece clave. Lo fundamental del método está en que quienes leen el evangelio lo hacen desde el seguimiento de Jesús, un seguimiento integral, es decir, no intimista, ni sectario, ni tampoco meramente sociopolítico. Si no es éste el caso y se lo lee de manera puramente intraeclesiástica, el resultado es otro. Si en épocas pasadas, algunas veces se lo vació, al utilizarlo de modo militante, al servicio de una organización, ahora se lo vacía, cuando se deja de lado la pretensión histórica y pública de Jesús.

11. Además de los autores citados en la nota 9, véase Trigo, "Lectura orante comunitaria de la palabra de Dios", Revista Latinoamericana de Teología 51 (2000) 293-307. 
Después de haber visto cómo se descubre a Jesús en los evangelios, es preciso insistir en que Jesús de Nazaret, y no un Cristo inventado a nuestra imagen y conveniencia, es el pivote de la teología de la liberación. Hay que reconocer con honradez que ni el Cristo dogmatizado de la institución eclesiástica, ni el santo principal de la corte celestial del catolicismo popular, ni el Cristo abocetado de los cristianos modernizados recalaban en el Jesús de Nazaret de los evangelios. En América Latina, la persona histórica llamada Jesús de Nazaret, su vida concreta, paradigma absoluto de humanidad ${ }^{12}$ para los cristianos y para otros muchos que se remiten a él, aunque no son de los nuestros, era desconocido para la inmensa mayoría. Estaba muy presente, por vía ritual, su nacimiento, su pasión y su muerte (los ciclos de. Navidad y Semana Santa); pero entre ambos acontecimientos, todo era impreciso o había simplemente un gran vacío. La teología de la liberación, al insistir en que lo distintivo del cristiano es seguir a Jesús, ha puesto de relieve - y como algo central - toda la vida de Jesús. Más aún, ha liberado la narratividad de los evangelios de la hipoteca a la cual la había sometido la herejía oculta, pero pertinaz, que ve a Jesús como un Dios disfrazado de hombre. No cree que se va haciendo como nosotros, a través de su vida, no cree que va arriesgando a lo largo de su vida, sino que actúa "como si" Jesús ya lo es todo, desde el comienzo, ya lo sabe todo, ya lo puede todo, y por tanto, no arriesga nada. El gran aporte de la teología de la liberación al catolicismo popular es su historización, a través de la historia viva de Jesús de Nazaret. También la institución eclesiástica va llegando a ese encuentro con Jesús de Nazaret -aunque con más reticencia, porque ve la exigencia que conlleva-, que hoy y siempre es el mismo de ayer, aquel de quien nos hablan los evangelios.

El Jesús de Nazaret de la teología de la liberación es el Mesías pobre de los pobres, el que, como dice Puebla, "nació y vivió pobre en medio de su pueblo", el que vino a dar a los pobres la buena noticia de su liberación, el que los proclamó felices porque Dios les daba su reino, el que, desde los pobres, asumió la causa del ser humano como su propia causa, como la causa de Dios. La liberación que él promovió no fue, ciertamente, política, ya que no quiso ejército, ni súbditos, como los señores de su época, sino seguidores voluntarios. Pero ese mundo fraterno de los hijos de Dios que él promovió, levantando al pueblo abatido, y llevando a cabo un movimiento para reunirlos y unificarlos, donde nadie se sirviera de otros, imponiéndose sobre ellos, sino que prevalecieran las relaciones mutuas y el primero fuera el servidor de todos, fue mucho más revulsivo que una simple revuelta de un oscuro caudillo de provincia. Por eso, el título de la cruz, que era su sentencia, no fue una equivocación: como el pueblo lo siguió y le permaneció fiel hasta el fin, tuvieron que quitarlo de en medio, por el peso político de su propuesta.

12. Trigo, "Jesús de Nazaret, paradigma absoluto de humanidad", en Jesucristo, prototipo de humanidad en América Latina, México, 2001, pp. 85-128. 
Pero Dios lo reivindicó resucitándolo, es decir, levantándolo de entre los muertos para que viviera humanamente de él, como Padre, y del Espíritu. Jesús está en Dios como nuestro hermano, ya en él hemos llegado al corazón de Dios; y desde Dios, ha derramado su Espíritu sobre toda carne para que siga adelante su propuesta del reino. De esto es sacramento la Iglesia. Pero su cuerpo doliente en la historia son los pobres. Por eso, ellos son el primer sacramento de Jesús de Nazaret, de modo que lo que se les haga a ellos se le hace a Jesús, y de ayudarlos o no, depende nuestra humanización o nuestro fracaso humano.

Hay que decir que en nuestra época, este Jesús sigue siendo tan revulsivo como cuando vivió. No es claro que sea este Jesús el que proclama y sigue la institución eclesiástica, y ésta es una de las razones del silencio en torno a la teología de la liberación. Ahora bien, el que lo proclamen los teólogos de la liberación no equivale a que lo vivan. También para ellos, como para todos, la fidelidad es pascual: siempre lleva a algún género de muerte, la cual tendemos a rehuir, aunque para nosotros es el camino de la vida.

\section{Algunas propuestas significativas de la teología de la liberación}

La teología de la liberación suele ser relacionada más con la crítica a la dirección dominante de la presente figura histórica que con propuestas constructivas. Sin embargo, existen estas propuestas, tanto respecto a cómo vivir hoy de una forma alternativa y avanzar socialmente en aquello que se pueda, como respecto al horizonte utópico, el horizonte de los esfuerzos y de las luchas concretas. Mencionemos algunas líneas que vienen desarrollando los teólogos.

\subsection{El sujeto como trascendente}

La primera propuesta propicia la subjetualidad personal ${ }^{13}$. Nos parece que llegar a ser sujeto humano es una aspiración absoluta, y que el mismo Dios está dispuesto, por así decirlo, a colaborar para que se haga realidad, en cualquier circunstancia vital, incluso en el pauperismo, en el abandono, en la explotación o en la necesidad de multiplicarse para atender a múltiples quehaceres impostergables. Sujeto es el que vive desde su libertad liberada, es decir, una libertad que no vive esclavizada de sus pulsiones, deseos o quereres autonómicos y despóticos, sino que es capaz de obrar desde su corazón, desde la raíz de la cual brota su querer,

13. La revista Pasos del DEI, San José, Costa Rica, ha venido insistiendo sistemáticamente sobre el tema. Indicaremos sólo los números y las páginas: 79 (1998); 87 (2000); 88 (2000) 1-34: 91 (2000)18-24; 90 (2000)1-10; 103 (2002) 10-28; 104 (2002) 1-23; 106 (2003) 1-28,38-43,51-52,55-72. Además, Hinkelammert, El grito del sujeto, San José, 1998; Trigo, Dar y ganar la vida. La condición del sujeto desde la perspectiva cristiana, Bilbao, 2005; Ortiz, "Ethos religioso y modernidad en América Latina", Stromata $L V$ (2004) 261-292. 
desde el núcleo en el cual se origina su humanidad, desde esa matriz en la cual se despliega la multiplicidad y, a la vez, se entrelaza y encauza. Esta libertad, por estar liberada, no se realiza imponiéndose a otros, sino sirviéndolos y realizándose personal y humanamente, en esa entrega.

Hoy todo conspira para que el ser humano no pueda realizarse como sujeto. El totalitarismo de mercado no puede funcionar con sujetos humanos. Por eso, hace lo imposible para secuestrar su libertad, seduciéndolo para que se haga adicto a sus propuestas - sus mercancías-, y obligándolo a capacitarse para aquello que se le propone, so pena de quedar fuera de nuestro mundo. Se le pide que se limite a ser miembro de conjuntos. Si acepta definirse por lo que tiene vigencia, se le hace saber que tiene que esforzarse al máximo y de forma incesante, porque la competencia no cesa; pero también se le promete que cuanto más ascienda, se le abrirán horizontes de satisfacción más amplios, casi ilimitados e inabarcables. Es muy difícil no embarcarse en este juego, nadar y guardar la ropa, vivir sin llegar a entregar el alma. Pero lo que se propone, en verdad, el sujeto es otra cosa: llegar a vivir y a dar vida. Capacitarse de tal modo que consiga medios para vivir en la acción misma de ayudar a otros, vivir conforme a una vocación, de manera que el trabajo sea, a la vez, medio y modo de vida. En cualquier caso, no perder el alma, ni siquiera a cambio de la vida. No es que el sujeto llegue a lograr todo esto, pues la condición de sujeto no es la de quien posee y almacena, pero esto le ofrece una dirección vital. Ser sujeto es vivir en este horizonte y tender hacia él.

Sólo quien es sujeto de este modo puede emprender una lucha de liberación, en cualquier campo. Claro está, la acción, tal como dijimos antes, acrisola esta subjetualidad, pero sin una subjetualidad mínima no cabe acción trascendente. Así lo dice perspicazmente Medellín: "La originalidad del mensaje cristiano no consiste directamente en la afirmación de la necesidad de un cambio de estructuras, sino en la insistencia en la conversión del hombre, que exige luego este cambio. No tendremos un continente nuevo sin nuevas y renovadas estructuras; sobre todo, no habrá continente nuevo sin hombres nuevos, que a la luz del Evangelio sepan ser verdaderamente libres y responsables" $(1,3)$.

La teología de la liberación presta una atención especial y concede una importancia de primer orden al aumento de la subjetualidad popular. Y ello por dos razones. La primera, porque si Dios opta por los pobres y les concede su reino, lo que él más quiere es que sean sujetos, aunque, por otra parte, hay que decir que nada contribuye tanto al surgimiento y a la consolidación de la subjetualidad popular como el que se les dé fehacientemente la buena nueva de que Dios quiere relacionarse tan íntimamente con ellos que esa relación lo caracteriza como Dios de los pobres. Sin embargo, la afirmación más radical de esta teología sostiene que los pobres se dejan llevar por el Espíritu. En efecto, si los que no tienen medios para vivir, viven, lo hacen por el impulso del Espíritu dador de 
vida $^{14}$. Esto no significa que no resistan al Espíritu o que no se dejen llevar por otros espíritus. Significa sólo - y nada menos - que en cuanto se dejan llevar por el empeño agónico por vivir, obedecen al Espíritu, con independencia de si se percatan que siguiendo ese impulso, siguen al Espíritu de Dios. Ahora bien, es un hecho que muchos pobres latinoamericanos, no sólo siguen al Espíritu, sino que la fuerza que los ayuda a esta docilidad a la vida, que les es negada por el sistema, no es otra que la fe en Dios.

La segunda razón por la que la teología de la liberación está empeñada en la subjetualidad popular es porque sólo desde ella será posible la lucha que no cesa por la liberación. Si los pobres no son sujetos, su única esperanza es que otros los hagan valer, otorguen valor a sus vidas. Pero la salvación sólo recibida no sería auténtica liberación humana.

También sabemos que, si es verdad que sin el pueblo no se salva al pueblo, también es verdad que el pueblo solo no se salvará a sí mismo. Por eso y porque, como cristiana que es, la teología de la liberación quiere seriamente la salvación de todos, está también empeñada en la subjetualidad de gente no popular. Esta corriente teológica afirma que el ponerse al servicio de la liberación popular, es la fuente más genuina de subjetualidad. Pero con la condición de que ese servicio se haga desde lo más auténtico de la persona, de manera que la entrega a los demás la constituya también en sujeto.

\subsection{Contribución a la emergencia de los nuevos sujetos sociales}

Sólo verdaderos sujetos humanos pueden emprender la lucha por la emergencia de los nuevos sujetos sociales. Ya lo hemos dicho. Ahora queremos insistir en lo que toca a la condición de sujeto de los sujetos sociales. Emergen sujetos sociales cuando su acción tiene peso y cualifica las estructuras, las instituciones y la acción del conjunto. Pero este peso puede aplastar a otros. Este colectivo puede buscarse un lugar a costa de otros, puede subir subordinando a otros, quienes de dominantes pasan a ser subalternos. Es el clásico "dar vuelta a la tortilla": el conjunto queda igual, sólo sus componentes cambian de posición. No deseamos que estos sujetos emerjan como aquellos que les han precedido. Buscamos que emerjan creando nuevas posibilidades, como riqueza para todos. No se puede ocultar que la inclusión de los excluidos lleva, de buenas a primeras, a que tenga que repartirse entre más lo que hay. Incluye, por tanto, un sacrificio. En ese sentido, cabe hacer una cierta fuerza, lo más justa y democrática posible, para que los acaparadores entren en razón. Pero el acto de justicia no puede consistir sólo en una mera redistribución; es preciso que contenga nuevos horizontes, posibilidades renovadas o inéditas, un aumento de productividad social, una verdadera aventura his-

14. Trigo, "Evangelización del cristianismo en los barrios de América Latina", Revista Latinoamericana de Teología 16 (1989) 94-108. 
tórica en la cual haya un lugar para cada grupo, para la capacidad y la creatividad de cada cual, para cada interés legítimo. Este es el punto que aporta la teología de la liberación al movimiento de emancipación de cada sujeto social: le hace ver, a la vez, la justicia de su causa, las tentaciones que debe vencer para lograrla, sin traicionar su impulso liberador, y la oportunidad de crecimiento y trascendencia que lleva aparejada.

\subsection{El cultivo de las culturas emergentes: trascendencia y desviaciones}

La emergencia de los nuevos sujetos tiene una fuerte impostación cultural, ya que esos nuevos sujetos son, a la vez, etnias y culturas. E incluso lo étnico llega a la categoría de tal, sobrepasando el nivel de los rasgos meramente raciales, por la elaboración cultural que lleva aparejada. No es sólo un mero origen común, perceptible en una serie de rasgos diferenciadores. Es sobre todo el peso y el poso de una historia compartida.

A este nivel, la teología de la liberación tiene dos aportes. El primero es subrayar la relevancia de lo cultural ${ }^{15}$. Los nuevos sujetos son seres culturales y su emergencia es, por tanto, la emergencia de sus culturas. Emerger no es subir en la escala social, dejando atrás su ser cultural y asumiendo el occidental, vigente hasta hoy. Ésa fue la propuesta modernizadora: quienes iniciaron la democracia popular, que superó la sociedad señorial, mediante la creación de los partidos de masas y la educación masiva de calidad, dieron un paso adelante, en la historia de América Latina, que debemos valorar en gran medida. Pero al captar certeramente que sin la asimilación de los bienes civilizatorios y culturales de la modernidad, la región no tenía futuro, dedujeron de forma errónea que asimilar estos bienes equivalía a dejar de ser lo que eran para ser occidentales sin más. Para ellos, modernizarse equivalía a occidentalizarse, ya que la cultura occidental fungía en ellos como el paradigma civilizatorio universal. Crecer en humanidad era dejar atrás sus culturas, vistas como particulares, como provisionales, y entrar en la cultura occidental, que era para ellos la cultura del mañana, la cultura universal, la cultura sin más.

La teología de la liberación insiste en que Dios no quiere que la humanidad se rija por el paradigma de Babel: la homogeneización de los seres humanos, que se entiende en una sola lengua, que está regida por las mismas reglas de juego y está dirigida al mismo propósito. Dios no aprueba esta dirección histórica, que entraña una sociedad piramidal, en la cual las hormigas (la mayoría encuadrada en la cultura de masas) trabajan para la gloria del conjunto - la de quienes comandan el proceso-, y que acarrea un tremendo empobrecimiento humano -el costo del éxito de la subordinación de todos al único fin, el de los dirigentes. Este proyecto fascina, por su carácter descomunal, y por su peso, que

15. Scannone, “Cultura mundial y mundos culturales”, Stromata LII (1996) 19-35. 
se presenta como incontrastable, hace surgir construcciones que parecen sobrehumanas y aplasta a quien se le opone. Dios no quiere, pues, que las culturas de los sujetos que emergen, que hasta hoy han vivido como subalternas, sean abandonadas por éstos como si fueran pura inferioridad y retraso, una limitación de la cual es preciso deshacerse a toda costa.

El paradigma que Dios quiere para la historia es el de Pentecostés: cada oyente escucha en su propia lengua las maravillas que Dios obró en Jesús: el mismo acontecimiento llega refractado por la multiplicidad de culturas, cada una de las cuales retiene y asimila unos aspectos más que otros y organiza el conjunto, desde sus propios ejes. $\mathrm{Y}$ a su vez, cada cultura es fecundada y trasformada por ese acontecimiento. La única salvación se vivencia de maneras distintas y complementarias. Así como el único acontecimiento de Jesús de Nazaret es narrado de modo diverso, por cada uno de los cuatro evangelios, y cada uno lo expresa verdaderamente, es el conjunto el que lo expresa en su totalidad. De ahí, la legitimidad de cada evangelio, su carácter insustituible, y la necesidad complementaria del diálogo de perspectivas. No hay posibilidad de construir un solo evangelio con la suma de los cuatro, hay que mantener cada construcción como tal, y hay que ponerlas en diálogo permanente. Lo mismo vale para las culturas. Todas contienen humanidad, cada una aporta riquezas específicas, pero ninguna contiene la humanidad cabal. No tiene sentido la pretensión de construir una supercultura, que contenga lo mejor de todas. No hay otro camino que, mediante la acción en cada una y la influencia mutua, trascenderse cada una desde dentro y, además, dialogar incesantemente entre sí.

El segundo aporte de la teología de la liberación, complementario con el anterior, es advertir a las culturas que no pueden asumirse de modo compensatorio. Es una gran tentación en la cual se está cayendo de forma masiva: plegarse de modo acrítico al mercado totalitario y utilizar la cultura propia y particular, no ya como el cauce por el cual una sociedad llega a satisfacer sus necesidades humanamente y a proyectarse y autotrascenderse, sino como seña de identidad sacralizada. En los mitos, los símbolos y los ritos, la comunidad encuentra el sentido que no le da la participación exitosa, en el mercado. Este sentido es espurio, porque no nace de la vida social, sino de precipitados históricos que han sido deshistorizados y sublimados, y además, sacralizados. $\mathrm{Y}$ al encontrar el sentido por esta vía barata y autocomplaciente, se evita la necesidad de transformar el modo corporativizado del mercado, de modo que se puede coexistir pacíficamente con la deshumanización, producida por la participación en una situación de pecado, la cual favorece a sus intereses.

Esta manera de vivir la cultura es tremendamente nociva, porque con ella culmina la sacralización de la vida social. Si por un lado, el mercado está sacralizado, al ser absolutizado, para impedir que le impongan las regulaciones que podrían salvarlo, y si por el otro lado, también se sacraliza la cultura, vivida al margen 
del mercado, entonces, ya no queda espacio para la fluidez de la vida, para la apertura de la historia. Para devolver al mercado, por un lado, su apertura, la auténtica competencia, sus límites, porque no todo en la existencia humana se puede transar con todo. Y para devolver a la cultura, por el otro lado, su constante transformación por la acción de los sujetos (en el sentido trascendente, aludido más arriba) y por el diálogo intercultural.

Quiero hacer notar que hasta ahora, en la teología de la liberación ha predominado el primer aporte sobre el segundo, y creo que el'segundo salvaguarda el carácter trascendente del primero e impide la confusión de promocionar la cultura, sin percibir que se la está promoviendo de modo larvadamente fundamentalista.

\subsection{La cotidianidad: el ritmo y la polifonía de la vida}

En unos casos, por hacer de la necesidad virtud y, en otros, por un genuino descubrimiento, lo cierto es que la teología de la liberación está prestando una atención creciente a la cotidianidad. Privilegiar la cotidianidad significa expresar el predominio de la vida sobre la historia, significa reconocer, sí, que la vida humana es histórica, pero que este carácter histórico le incumbe a la vida, es decir, que no es para desvivirse, sino para cualificar la vida, para evitar que se naturalice, ya que la vida humana, a diferencia de la de los animales, no está regida por el instinto, sino por la elección consciente de sus objetivos y la invención de los medios para lograrlos, todo ello en una espiral incesante.

Occidente ha caído en la desviación de que la acción técnica y el consumo han alcanzado tal desarrollo que no son ya, en realidad, dimensiones de la vida, inscritas en la matriz de la vida humana, que les otorga su función y sus proporciones, sino que se han vuelto autónomos, distorsionando la vida. Atenerse a la cotidianidad significa, entonces, recuperar las dimensiones preteridas, y devolver la producción y el consumo a sus debidas proporciones, reinsertándolas en el conjunto, no persiguiéndolas de modo absoluto, sino de manera que cumplan la función que les compete, en el conjunto.

La cotidianidad no es, pues, simplemente lo que, de hecho, se vive cada día, sino la recuperación de la pluriformidad de la vida con sus múltiples dimensiones y con su ritmo. No se trata, pues, del ritmo frenético del circuito de la producción y del consumo, necesario para el mantenimiento expansivo del mercado totalitario, pero que sacrifica la vida humana como tal.

No se puede recuperar la cotidianidad y no se puede reinstaurar su ritmo, si no nos liberamos de la compulsión de hacernos cada día más productivos para ocupar un puesto mejor, para ganar más y poder consumir más y mejor. Esto significa que la cotidianidad es el ámbito de vida del sujeto. Y es una prueba muy adecuada para verificar cuándo la entrega a una causa es una acción, en el sentido trascendente aludido, o un mero trabajo altruista, que no construye al sujeto. 
En el ambiente en el cual se nos vende la fragmentación como el modo más llevadero de estar a gusto, sea en el trabajo, sea en la familia, sea en el voluntariado, sea en el movimiento eclesial, y sin perturbaciones de conciencia, es importante advertir que la cotidianidad cualitativa de la cual hablamos exige que cada dimensión de nuestra vida se articule en la trama inconsútil de nuestra única vida. El mismo sujeto vive en cada nivel y campo de acción, en cada ámbito de vida. Si el que me conoce en un campo no puede ni sospechar lo que yo soy en los demás, es que no soy un sujeto, sino un mero elemento de los diversos conjuntos a los cuales pertenezco, cada uno de los cuales sigue su propia lógica. Aquí se ve la extrema dificultad de ser sujeto. Es cierto que el sujeto no es una mónada, que vive de modo autista, pero sí es un núcleo del cual manan convicciones, razones, deseos, sueños, quereres y elecciones. Está en un grupo desde el cual se abre a los otros sujetos e interactúa con ellos. No es meramente alguien que piensa lo que se piensa, dice lo que se dice y hace lo que se hace. $\mathrm{Y}$ en la fragmentación que hoy se impone, eso es, precisamente, lo que se busca: un modo desimplicado y conductista de ser y estar. Desde el ambiente dominante, la coherencia es un fardo insoportable, pero desde la pretensión de ser sujeto es no sólo una exigencia irrenunciable, sino un tesoro que se cultiva con todo esmero

Entre esas dimensiones irrenunciables que hay que componer con las demás, una que tiene hoy especial relevancia, es la de ciudadanía. Todo nos empuja a dejar en manos de otros los destinos del conjunto. Se nos insiste constantemente que la política es sucia, además de que su complejidad inextricable la liga de forma inexorable a los expertos. Se nos quiere reducir a la condición de espectadores, que tienen derecho para aplaudir o denigrar a los que actúan, pero que no tiene sentido cambiar de papel y pretender actuar. Y sin embargo, estamos asistiendo al surgimiento de una ciudadanía activa, que se conecta de manera vertiginosa y con una eficacia sorprendente. La teología de la liberación apuesta por esta repolitización de la sociedad, mucho más capilar que la del período anterior, mucho más personalizada, más fluida, mucho menos ideologizada, pero no menos exigente ni comprometida.

Por lo menos, desde mi experiencia, creo que puede decirse que mucha gente popular vive una cotidianidad cualitativa. Un teólogo puede dedicarse a estudiar, a dar clases y a escribir y a emplear su tiempo libre en lecturas, espectáculos, paseos, viajes o en acción pastoral. Pero mucha gente popular tiene que trabajar como puede y en lo que puede, normalmente en varias cosas. Además, tiene que llevar la familia y la casa, incluso está siempre acabándola de construir. Tiene asuntos que resolver de la vida del barrio, desde la infraestructura material y los servicios a problemas con los adolescentes o las bandas de distribuidores de drogas, desde lidiar con la municipalidad a pertenecer a grupos - y están los compadres, los amigos y los vecinos con quienes se desarrolla la convivialidad. Eso sin contar con las enfermedades de pobres, que casi nunca faltan y la falta de trabajo y la 
violencia ambiental... Todo esto hay que hacerlo a la vez, o mejor dicho, y ahí está el secreto, hay un tiempo para cada cosa. Esto significa que se pasa del trabajo a la convivencia, del encuentro al consejo, del funeral a la echada de agua, de la risa al llanto, del sudor a pulirse, porque hay una reunión en la escuela o en el grupo, o hay una fiestecita. Al ser la realidad tan multifacética, la persona pasa de un registro a otro, y ése es el secreto de la salud humana, del equilibrio, de la constitución del sujeto. Hay que reconocer que es muy difícil tener que cargar con tantas cosas; es, sin duda, excesivo, y no pocas veces, la gente parece que no puede más. Pero también es cierto que en una u otra de esas actividades encuentra gracia, contento, se encuentra llevado y sostenido, a la vez que ayuda a edificar. Cuando el teólogo de la liberación ha superado la relación ilustrada y accede a este ritmo de vida, sabe realmente lo que es la cotidianidad, aprende a valorarla y comprende lo que está en juego, en el empeño de reinstaurarla.

\subsection{Religión con religación: el sujeto como hijo y hermano}

Un aspecto que diferencia profundamente a nuestra época de la anterior es el renacimiento de lo religioso, el reencantamiento de la naturaleza y de la persona ${ }^{16}$. Ya se ha consolidado lo que el Concilio llamó la sana secularidad, que consiste en la autonomía de las personas y las sociedades, así como de las diversas dimensiones de la existencia, respecto de la autoridad de la institución eclesiástica. Sin embargo, esta autonomía no ha supuesto el fin de la religión, sino una búsqueda mucho más personal, por un lado, y ofertas variadísimas, en el espectro del mercado y más allá de él, por otro lado. Lo que más salta a la vista es lo más pintoresco. Es lo que podemos llamar una gracia barata, es decir, ofertas dirigidas no tanto a la relación trascendente y comprometida, sino sobre todo a la resonancia interior, al entusiasmo. A eso se le llama, en muchos ambientes, experiencia religiosa: no interesa tanto el estímulo que la causa, cuanto lo que pone a vibrar dentro de la persona.

En este ambiente, la teología de la liberación insiste en el valor sanador y liberador de la relación con el Dios de Jesucristo. Esa relación otorga al sujeto una profundidad que no se logra de ninguna otra forma. Pero no es profundidad esotérica, sino profundidad en la realidad. Esa relación con Dios, si es verdadera, lleva a relacionarse realmente con cada persona y en cada nivel de realidad, lleva a estar en la realidad, a ser honrado con ella, a encargarse de ella, a la vez que uno se experimenta potenciado por la misma realidad. Pero el altísimo valor de la relación con Dios sólo se realiza cuando la relación es incondicionada, cuando no es utilitaria, cuando se lleva a cabo como una confianza sin límites y una disponibilidad, en principio, absoluta. La teología de la liberación nació profunda-

16. Scannone, "La religión en la América Latina del tercer milenio", Stromata LI (1995) 75-88; "La religión del siglo XXI: ambigüedades, tensiones, conflictos", Stromata LV (1999) 189-199. 
mente religiosa, pero ahora lo es más, o mejor dicho, se ha ido aquilatando, a lo largo del tiempo, y por eso está en condiciones de ofrecer a esta época una propuesta consistente.

Para el cristiano, el sujeto se realiza como persona a partir de dos relaciones trascendentes: la de hija e hijo de Dios y la de hermana y hermano de los demás. Según la fe cristiana, pertenece al sujeto abrirse confiadamente a recibir la vida de Dios. Lo más hondo del sujeto no es la acción, sino la apertura para que Dios se le autocomunique. De este modo, lo más profundo de la persona es ser hija de Dios. Esto significa que la persona no se funda en sí misma, no nace de sí, no es hija de sus obras, sino que se acepta como puesta en la existencia por otro. Se puede aceptar como de otro, porque ese otro no la crea para servirse de ella, sino que le da el ser como don de amor; más aún, no le da sólo el ser lo que es, sino que se da a sí mismo. En eso consiste propiamente ser hijo. Somos creaturas, porque Dios nos da nuestro ser; somos hijos, porque Dios nos da su ser. Aceptarme como hijo de Dios es aceptar que lo más hondo que tengo es ser don de amor. Así, pues, el primer elemento del sujeto es la aceptación del don que lo constituye. Esta aceptación toma la forma de confianza primordial, de fe en el amor personalizador que constituye a la persona. Este amor aceptado se expresa amando. Por eso, el Nuevo Testamento insiste en que el que ama, ha nacido de Dios y se relaciona íntimamente con él, ya que vive a partir de él. Practica a Dios, porque Dios es Amor.

La correspondencia al amor de Dios tiene dos armónicos fundamentales: la entrega a realizar la obra del Padre y la entrega a los hermanos. En realidad, es lo mismo, visto desde dos perspectivas complementarias. El designio del Padre no es otro que la constitución del mundo fraterno de las hijas e hijos de Dios, y la realización de la fraternidad es rigurosamente trascendente, ya que sólo el Espíritu de hijos puede hacer nacer ese amor que no se funda en la arqueología del sujeto, en los lazos de carne y sangre, ni en el interés propio, ni en la mera complacencia. La prueba de que hay auténtica fraternidad es la ayuda horizontal y mutua a los pobres y el hacer bien a los enemigos.

En épocas anteriores, se nos decía, desde la izquierda, que dejáramos para más adelante el tema de Dios - que separaba a creyentes y no creyentes - y que acometiéramos juntos el de la liberación del oprimido como signo de la realidad de nuestro amor, que es lo que nos unía. Ya entonces resultaba claro, y hoy lo es mucho más, que el amor a Dios es la mejor salvaguarda contra la propensión que tiene el amor a los hermanos a degradarse en amor a los míos, lo cual ya no es amor, sino egoísmo de grupo. Hoy, lo religioso, entendido como esta relación con Dios y sus expresiones simbólicas, desde la oración a las expresiones comunitarias, está muy valorado. Pero a su vez, debe ser salvaguardado para que no se degrade a mero entusiasmo sin religación. Y la prueba que pone el Nuevo Testamento para comprobar si amo a Dios es el amor al hermano, en el sentido preciso del que venimos hablando. 
Quienes hoy escriben sobre el sujeto como trascendente se fijan en un punto que tenemos que reconocer como expresión primaria de la calidad de nuestro amor: el respeto al otro, la salvaguarda de sus derechos y la colaboración con su justa causa. Sin este respeto primordial, el amor no es tal, ya que se traga al otro. Es bueno insistir en este punto, porque el amor, al ser una protopalabra enormemente motivadora, tiende a ser prostituida y devaluada, vaciada de su genuino sentido. Por eso, las especificaciones que objetivan la calidad de nuestro amor son hoy muy pertinentes.

Quisiera decir que una de las gracias que he recibido de gente popular cristiana es percibir lo liberador que resulta vivir en la presencia del Dios de Jesús, hablando libremente con él, procesando con él la vida entera. La gente popular no reza el rosario cuando está sola, incluso, fuera de momentos ritualizados, como al levantarse o al acostarse, no reza oraciones aprendidas, sino que habla con Dios con sus propias palabras, de un modo personal, tanto que se puede decir que esta comunicación con él es la relación más personal que tienen; más aún, es una fuente permanente de personalización ${ }^{17}$. El teólogo de la liberación que supera la relación ilustrada con el pueblo, percibe en este modo que tienen ellos de vivir la religión, un hondo motivo de inspiración.

\subsection{Una propuesta paradójica de vida feliz}

Una novedad de la teología de la liberación, en estas últimas décadas, es la atención prestada a la calidad de la acción, insistiendo en que tiene que ser siempre una acción no de un mero agente, sino también de un paciente, es decir, una acción que, además de lograr el efecto objetivo que se propone, humanice y haga feliz a quien la lleva a cabo.

No se puede negar que, en la época pasada, hubo una cierta contaminación del modelo de acción de la izquierda, acción típicamente ilustrada, de un tipo humano, que se definía por pensar y actuar correctamente, que era un agente, alguien para los demás, un ser humano que pone entre paréntesis su yo empírico para consagrarse a la causa. Es lo que se llamaba un militante, alguien que se define por su pertenencia a una organización social y política, ya que los demás aspectos de su ser los considera secundarios, de algún modo, residuales. Esta pertenencia y esta entrega llegan a su máxima expresión en el liberado, aquel que se consagra de forma exclusiva a la causa, de modo que la organización corre con sus gastos y lo libera de la necesidad de invertir tiempo en un trabajo, que le permita ganarse la vida.

17. Seibold, "Experiencia simbólica, experiencia religiosa y experiencia mística" Stromata LVIII (2002) 263-296; "La mística de los humildes", Stromata LIX (2003) 21-62; "La mística popular como conjunción de fe y razón en América Latina", Stromata LX (2004) 191-228. 
Este tipo humano, blindado internamente y dedicado íntegramente a la acción, no nos parece hoy un ser humano integral. Primero, porque su acción no puede ser sólo para los demás, ya que él, como los demás, necesita de esas transformaciones; también él, como los demás, es un ser de necesidades. El objetivo de su acción no puede ser sólo la transformación superadora de la clase popular o la toma del poder. El objetivo insoslayable de su acción tiene que ser también su propia constitución como ser humano. Su humanización no es una consecuencia automática de consagrase a los demás. Es cierto que quien se empeña en conservar su vida la pierde y que quien la pierde, la gana. Eso sucede así, pero no siempre. Está abierta la posibilidad de perder la vida y no recobrarla. Y así ha pasado no pocas veces. Al cabo de años de lucha, mucha gente no ha llegado a poseer una humanidad cabal, sino que se encuentra endurecida o decepcionada o entregada meramente a su pasión dominante. Pero, además, tampoco la acción produjo en esas ocasiones más liberación humana, sino más poder para la organización y más fanatización de las masas. La experiencia ha sido lo bastante larga y compleja como para haber caído en la cuenta de que el heroísmo y la buena intención no redimen acciones poco lúcidas o sectarias.

Así como hay personas - es frecuente entre los emigrantes - que planean poner entre paréntesis su vida, desvivirse quince o veinte años para dedicarse a ganar dinero, de manera que el resto de su vida puedan dedicarse sólo a vivir, sin darse cuenta que el desvivirse, esto se convierte en su modo de vivir, y por eso, retrasan indefinidamente el regreso porque, en realidad, ya no saben sino trabajar; así también hay revolucionarios y agentes pastorales y teólogos, en la onda de la liberación, que han puesto entre paréntesis su vida para dedicarse a la causa popular, y no se dan cuenta que esta dedicación exclusiva los ha unidimensionalizado y que ya no pueden liberar a nadie, sino que necesitan que otro los libere a ellos de su alienación, no por consentida menos real y dañina.

El liberado - y con frecuencia también el agente pastoral- desconoce la cotidianidad, las relaciones personales bidireccionales, la gratuidad, el silencio, la fiesta, el descanso... Desconoce algo tan humanizante como pedir ayuda, pedir compañía, pedir consejo. Una persona así no es humana; es una máquina de acción, en el mejor de los casos, superdotada e incluso rica en cualidades humanas y, por eso, capaz de producir muchas cosas valiosas. Pero desconoce la dimensión estrictamente personal y, por eso, no es un sujeto, en el sentido aquí explicado.

Un verdadero sujeto no hace nada para otros que no sea también para sí, su acción es siempre transitiva y recae también sobre sí mismo. Pero además, un verdadero sujeto siempre reserva tiempo para que otros lo alimenten, lo edifiquen, lo hagan feliz, lo mismo que él trata de hacerlo con los demás.

¿Cómo se puede olvidar que la primera palabra realmente emblemática del sermón de la montaña, tanto en la versión de Mateo como en la de Lucas, es "felices"? No es que Jesús produzca un tratado sobre la felicidad, pero declara 
felices a ciertas personas, a quienes, por lo general, se juzga infelices, y a otras que tienen determinadas actitudes, y él quiere que todos sean felices. Es decir, tanto el Dios de Jesús, quien hace feliz, como Jesús, que lo proclama y es el feliz por antonomasia, quieren la felicidad para los seres humanos y es lo que les dan. Claro está que es una felicidad contracultural, paradójica, respecto a la opinión vigente; pero, por sus caminos propios, los únicos que la proporcionan verdaderamente, ellos la proclaman y la otorgan. Una propuesta cristiana, por muy esforzada y ortodoxa que sea, si no proporciona felicidad, no es de Jesús.

Esto debe ser hoy puesto de relieve, no para entrar en el mercado de sucedáneos baratos de felicidad, pero sí para reivindicar este armónico de la propuesta cristiana, dejado de lado por presentaciones del cristianismo demasiado ligadas a la ética y a la política, tal como las concibe la ilustración; demasiado vinculadas a la transformación del mundo, mediante un esfuerzo heroico, inteligente y tenaz, llevado a cabo por personas que se conciben a sí mismas como agentes. Estos sujetos, generosos y responsables, se podrán sentir satisfechos con la misión cumplida, pero no felices. La felicidad es lo propio del hijo que confía absolutamente en la capacidad que tiene el amor del Padre para colmar el corazón. Con esta esperanza, se entrega al servicio del reino. Es lo propio de quien vive la fraternidad que nos alcanzó Jesús y que desde esa relación, trabaja, lucha, colabora y comparte. Si somos cristianos, la felicidad ha de ser una aspiración irrenunciable, aunque no perseguida con ansiedad, ya que sabemos que es un don que acarrea una tarea, y sobre todo un estilo de vida.

\subsection{La utopía y la esperanza de vida fecunda para los pobres y en ellos para todos}

La teología de la liberación se concibe, en definitiva, como una teología de la esperanza. Promete felicidad como un armónico de fondo en la vida, pero no promete éxito, ni lo asegura. Se pone al servicio del reino, pero, como Jesús, no sabe el día, ni la hora. Hace todo lo posible porque se superen situaciones de injusticia y exclusión, busca denodadamente-el empoderamiento de la gente popular y sinergias de largo plazo con gente no popular. Entra en el terreno de la política, busca renovar la cultura, entra en red con quienes buscan en campos muy diversos alternativas superadoras. Pero sabe que ninguna construcción sociopolítica es capaz de superar, de una vez por todas, las alienaciones, las opresiones, las exclusiones, las injusticias. Se esfuerza por lo posible, tratando de que las mejoras se estabilicen para intentar otras nuevas ${ }^{18}$. Pero sabe que, con frecuencia, buscando el bien mejor, se encuentran males no previstos. Sabe que la acción humana es siempre ambivalente. Que nunca llegará a algo simplemente bueno,

18. Jung Mo Sung, "La teología de la liberación entre el deseo de abundancia y la realidad de la escasez", Pasos 110 (2003) 1-14. 
sino sólo a algo que contenga más bien que mal. El que los resultados de las acciones más inteligentes y mejor intencionadas sean siempre ambivalentes, no lleva renunciar a la acción, porque palpa lo mucho que significan las mejoras concretas. Sin embargo, no se queda en esas mejoras. Por el contrario, las proyecta en un horizonte mucho más elevado, el de las promesas de Dios. Y sobre todo, le mueve la firme esperanza en lo que no tiene nombre, porque su medida no es humana, sino el mismo Dios. Es decir que, luchando como si todo dependiera de él y de los demás, en definitiva, deja, esperanzado, su destino y el de la humanidad en las manos de Dios, sabiendo que él tiene para nosotros algo infinitamente superior a todos nuestros sueños.

Además de la esperanza que no falla, ha recibido de Dios símbolos esperanzadores, que le ofrecen directrices para su acción, para su horizonte concreto, para el sueño que se le invita a soñar, para el proyecto que tiene que ofrecer como buena nueva de Dios y que ha de construir con los demás, para ir acercándose siempre más a esa meta. Son los símbolos de los profetas.

Hay un símbolo profético especial: "Construirán casas y las habitarán, plantarán viñas y comerán de sus frutos, tendrán hijos y no se malograrán. No construirán ni plantarán para que se aprovechen otros, no engendrarán hijos para la catástrofe". Es la utopía del trabajo no expropiado y de la vida que no se malogra antes de tiempo, por la violencia y las enfermedades de pobres. ¡Parece tan poco! Y sin embargo, para la inmensa mayoría de la humanidad es una realidad mucho más lejana que hace, por ejemplo, cuarenta años, una realidad que hoy se presenta como completamente inasible. En el modo de producción actual, no hay trabajo productivo para más de la mitad de la humanidad, y de esa mitad que trabaja, por lo menos otra mitad no ve provecho al trabajo, trabaja sólo para sobrevivir, no para que el fruto de su trabajo se haga más vida para él y los suyos. La vida ciudadana en los países del tercer mundo, y en algunos de los más poderosos del primer mundo, está organizada de tal manera que, la mayor causa de mortandad de los adolescentes y jóvenes pobres es la violencia y después las enfermedades de pobres. Los pobres siguen teniendo muchos hijos para que al menos alguno llegue a viejo. ¿Tenemos que resignarnos a que las cosas sigan así? ¿No es deseable, incluso una exigencia de humanidad, luchar por cambiar el modo de producción y la manera de ejercer la política, para que todos puedan tener un trabajo productivo y todos puedan levantarse sanos y en paz? Este cambio, a la larga, conviene a todos, pero a corto y mediano plazo, tiene un costo económico, que no pueden pagar los pobres, sino los que no lo son. Los que no son pobres, tendrán menos para gastar o invertir; pero si deciden poner sus dotes para organizar las cosas de otro modo y para ayudar a llevarlo a cabo, sin duda, que se desarrollarán humanamente y, además, ejercerán la fraternidad, que es la máxima expresión humana. Pero además, los pobres, que son la mayoría, tendrán que crecer para capacitarse y para luchar por sus verdaderos intereses, sin dejarse mediatizar, sin dejarse comprar por un plato de lentejas, sin venderse por un par 
de sandalias, incluso cuando no tengan para comer y para calzar. Nosotros podemos ofrecer - como escudo en los días aciagos - la fraternidad, capaz de lograr el milagro de la multiplicación de los panes, y la fe en Dios, que no nos deja de su mano y nos da la fuerza de su Espíritu.

¿Será esto sueño insensato? La verdadera insensatez, ¿no será dejar de soñar y resignamos a las migajas que arrojan hoy los opulentos? ¿No es irracional un modo de organizar la generación y apropiación de la riqueza y la vida política, que produce una brecha que está en peligro de volverse infranqueable? ¿Es vivible una humanidad separada por un abismo? Esa sima, ino es la mayor fuente de violencia? ¿No es bueno para todos encaminarnos en la dirección de una vida con oportunidades para todos, una vida con enormes dosis de emulación, pero con dosis aún mayores de sinergia y colaboración? ¿No es bueno soñar y proponerse una vida en la cual las personas tengan más valor que las cosas, que el dinero, que las mercancías? ¿No merece la pena pagar cualquier precio para lograrlo?

Se habla del fin de los grandes relatos. A nosotros no nos interesa saber si el que hemos propuesto es un relato grande o pequeño, pero sí sabemos que, para nosotros, es irrenunciable. Dejaríamos de creer en nuestro Dios, si renunciáramos a sus promesas. Y este relato que hemos bosquejado, es la expresión mínima del reino, de la fraternidad de las hijas y los hijos de Dios, que proclamó Jesús y por el cual dio su vida. El que el Crucificado sea el Viviente, nos hace estar seguros de que la última palabra no la tienen quienes absolutizan la libertad del capital y relativizan todo lo demás, incluso la vida humana. La causa de nuestro Dios es la causa del ser humano, el trabajo como fuente de vida y la vida lograda para todos.

Desde todo lo expuesto, concluya el lector si ha muerto la teología de la liberación. Sí quisiera precisar que no basta, como a veces se escucha, que haya pobres para que exista esta teología. Es preciso que la teología sepa fundamentar que la liberación de los pobres revela a Dios, forma parte del núcleo del evangelio que proclamó y practicó Jesucristo y es tarea imprescindible para constituirnos en seres cualitativamente humanos. Tiene que hacer ver cómo este eje transversal estructura toda la teología. Tiene que mostrar también cómo la Iglesia no es sacramento histórico de liberación, si no proclama y se compromete, siguiendo a Jesús, con la liberación de los pobres, y si no se estructura a partir de los pobres con espíritu. Tiene que mostrar además cómo esta propuesta es buena nueva también para los que no somos pobres.

Todo esto tiene que llevarlo a cabo a la altura de los tiempos, con fidelidad creativa. Pero, antes que nada, el teólogo debe comprometer su vida con los pobres de la tierra, como exigencia de fidelidad al Dios de Jesús, como seguimiento discipular a Jesús de Nazaret y como obediencia a su Espíritu. De todo esto depende que exista o no teología de la liberación. En este artículo, pensamos haber dado elementos para que el lector pueda formarse una opinión razonada al respecto. 